\title{
Evaluation of Clinical Teaching by Nursing Students at the Higher Institute of Nursing and Health Techniques in Casablanca, Morocco
}

\author{
Wissam ElMachtani ElIdrissi ${ }^{1 *}$ \\ Halima Lajane ${ }^{1}$ \\ Ghizlane Chemsi \\ Mohamed Radid ${ }^{1}$ \\ ${ }^{1}$ Laboratory of Physical Chemistry of Materials, \\ Ben M'Sik Faculty of Science, \\ Hassan II University of Casablanca, \\ Morocco \\ ${ }^{2}$ Multidisciplinary Laboratory of Science, \\ Technology of Information, \\ Communication and Education, \\ Ben M'Sik Faculty of Science, \\ Hassan II University of Casablanca, Morocco \\ ${ }^{*}$ Corresponding Author
}

DOI: https://doi.org/10.36941/jesr-2022-0032

\section{Abstract}

Clinical teaching is an integral component of nursing education. As such, nursing students' evaluations provide insight into their perceptions of this style of teaching. It's a type of evaluation that was devised to improve education through formative assessment. The students' point of view on the instruction they receive is a fundamental element since they are the main recipients, and they appear more and more as partners in the educational process. Therefore, the purpose of this study is to explore and describe students' perceptions of clinical instruction at the Higher Institute of Nursing and Health Technology in Casablanca. To address this, we have drawn from Knox and Mogan's (1985) model of effective clinical nursing teaching. The results obtained showed that the teaching ability dimension received the highest score (4.61 \pm 1.62$)$, followed by nursing competence, personality, and interpersonal interaction. Nevertheless, students gave the component of evaluation the lowest score (4.20 \pm 1.76$)$. With $p>0.05$ for all dimensions, the Mann-Whitney test reveals that the differences between the two groups of students are not statistically significant. For more accurate findings, however, further research is needed, and teachers and tutors should highlight the differences between the three groups.

Keywords: Clinical teacher, Clinical teaching, Nursing, Perceptions, Student Evaluation of teaching 


\section{Introduction}

Teaching in the clinical setting is an essential component of nursing education (Hsu, 2014). Compared to other controlled settings such as the classroom, laboratories and seminars (Bifftu et al., 2018), clinical teaching is complex. It involves not only the transfer of clinical knowledge but also the importance of acquiring affective attitudes, psychomotor skills, critical reasoning and clinical judgment necessary for professional nursing practice in authentic situations (Bifftu et al., 2018; Hsu, 2014).

This requires multiple avenues for clinical learning, mainly how to maintain relationships and interactions with patients and the team members in a way that keeps feedback ongoing (Hsu, 2014) and helps develop a very positive relationship with the clinical teacher. In order to maintain motivation among nursing students, ensure their satisfaction with the clinical learning experience and judge their performance effectively (Chan et al., 2017; Lillekroken, 2019; Salamonson et al., 2015a).

Moreover, clinical teaching occupies an important place in nursing education and is an essential component in determining the effectiveness of education. However, students and teachers face several difficulties such as the low availability of teachers in the clinical environment to support and monitor students (Otti et al., 2015), the challenge of dealing with students who have learning disabilities or have been through unpleasant clinical circumstances, the difficulty of assessing students and providing feedback due to the complexity that accompanies the documentation of their performance (Rodger, 2019; Takashima et al., 2019), the difficulty of providing diverse clinical learning opportunities (Salamonson et al., 2015b), the lack of opportunities for pedagogical and professional development (Brown et al., 2012; Selim et al., 2012) and how all these affect the expectations placed on clinical learning by students.

Indeed, Lovric et al. (2014) emphasize the need for several studies dedicated to exploring the effectiveness of the teaching provided by nursing schools and the recognition of the needs of nursing students (J. I. Cho et al., 2018). This tendency is gaining momentum especially through the adoption of the humanistic and holistic approach in teaching-learning (Zakari et al., 2014) which gives importance to the preferences (Hallin, 2014) and opinions of students (O'Mara et al., 2014; Papathanasiou et al., 2014), through the student evaluation of teaching (SET).

Students' evaluation of teaching should focus most on teaching characteristics such as assessment and learning environment that are adopted by teachers (J.-I. Cho et al., 2014; Otani et al., 2012). It can also lead students to evaluate several specific characteristics of teachers such as knowledge, clarity of explanations, organization, enthusiasm, friendliness, fairness, availability, accessibility, use of humor, and contribution to students' learning (Uttl et al., 2017).

The results obtained from student evaluation of teaching clearly distinguish between aspects of teaching that are of minimal importance and those that have a great influence on teaching because they are perceived by students when they formulate their overall assessment of the teacher's teaching and are likely to contribute to the improve awareness and responsiveness of teaching and faculty members (J. I. Cho et al., 2018).

In addition, SET can be formative and focus on a single course or on specific aspects of nursing such as clinical teaching (Bush et al., 2018).

According to Knox and Mogan (1985), clinical teaching is the set of actions, activities and expressions of the clinical teacher that facilitate student learning in the clinical setting (J. E. Knox \& Mogan, 1985). Through a detailed review of the literature, these authors developed a model of all the fundamental characteristics of clinical teaching, particularly those of the clinical teacher, called the Nurse Clinical Teacher Effectiveness Inventory (NCTEI). As a result, understanding the characteristics of clinical teaching and their various dimensions through student perceptions (Edberg \& Lilja Andersson, 2015; Lovrić et al., 2017) has a significant impact on diagnosis and decision making, contributing to the improvement of teaching effectiveness (Annan et al., 2013; Fraile \& Bosch-Morell, 2015; Setari et al., 2016; Zabaleta, 2007) as well as meeting the needs of students to ensure the graduation of future qualified nurses (Shahsavari et al., 2014). In this sense, Knox and Mogan's (1985) 
model of clinical teaching effectiveness provides a research framework which determines the five dimensions of clinical teaching: teaching ability, nursing competence, assessment, personality, and interpersonal relationship. These dimensions define also the relationship between student and teacher and the effectiveness of clinical teaching (J. E. Knox \& Mogan, 1985).

Inventory (NCTEI). It is a reference model, used extensively to assess the characteristics that facilitate the learning process in clinical teaching, through the perceptions of teachers, practicum tutors, and nursing students. Its goal behind identifying the most and least significant features is to offer a thorough assessment of the clinical instruction delivered by the instructor, and it serves as a foundation for enhancing training quality. (Gangadharan et al., 2016; J. E. Knox \& Mogan, 1985; Soriano \& Aquino, 2017).

This model describes five basic dimensions related to clinical teaching. These are teaching ability, nursing competence, evaluation, interpersonal relationship and personality (Gangadharan et al., 2016). These dimensions are assessed through specific items (Bifftu et al., 2018).

The teaching ability is the process of transmitting knowledge, skills, and attitudes (J. E. Knox \& Mogan, 1985; Nehring, 1990a). Furthermore, via interaction, engagement in the social environment, and use of cognitive resources in nursing practice, the teacher in clinical teaching mobilizes reflective learning in students. (Elcigil \& Sari, 2008; Parsh, 2009).

The influence of the clinical teacher's teaching skills is manifested through the socialization, professionalism, skill acquisition and maintenance of interpersonal relationships in students (Lee et al., 2002; Nahas et al., 1999).

Nursing competence is the sum of the clinical teacher's theoretical and practical knowledge, as well as his or her attitude and practice toward the nursing profession. (J. E. Knox \& Mogan, 1985; Nehring, 1990a).

Evaluation is an important part of clinical teaching. It is an indicator of the acquisition of clinical skills and a guarantee for the provision of quality patient care (Navabi et al., 2016). In addition, evaluation in clinical teaching is the type of feedback that the teacher gives to the student regarding his/her clinical performance and written assignments (J. E. Knox \& Mogan, 1985; Nehring, 1990a). However, it remains a complex process, whereby the teacher considers not only the application of knowledge and technical skills in specific clinical situations but also critical thinking and interpersonal communication. This is necessary to ensure the training of qualified nurses (Castro-Yuste et al., 2018; Kamonratananun et al., 2016).

The interpersonal relationship is the fourth dimension that characterizes clinical teaching. It is a state of mutual interest or communication between two or more people. It is far from any specific therapeutic communication between the patient and the nurse (J. E. Knox \& Mogan, 1985; Nehring, 1990a).

Personality encompasses individual attitudes, emotions, and character traits, which are not directly related to teaching, caring, or interpersonal relationships but have the potential to influence them all (J. E. Knox \& Mogan, 1985; Nehring, 1990a).

Therefore, the clinical teacher is a key player, his or her effectiveness is necessary for the training of future qualified nurses (Boyd \& Lawley, 2009; Lee et al., 2002; Shahsavari et al., 2014). In addition, the quality of the student's clinical learning depends on the quality of the clinical teaching provided and the characteristics of the clinical teacher (Lovrić et al., 2014).

The objective of this study is to explore and describe students' perceptions of clinical teaching in the nursing program at the higher institute of nursing and health techniques (ISPITS) in Casablanca.

More specifically, our research paper aims to engage with the following questions:

1. What are the students' perceptions of clinical nursing teaching?

2. Are there significant differences in students' perceptions of clinical nursing teaching? 


\section{Methodology}

\subsection{Research Design}

In this study, a cross-sectional survey design is adopted. The purpose is to investigate nursing students' perceptions of clinical education they receive.

\subsection{The context of the study}

The study is carried out during the academic year 2020 at ISPITS in Casablanca, Morocco, for the "Care Nursing" major.

\subsection{Sample and Data Collection}

The sample for our study consists of nursing students. The total number of participants is 138 students belonging to the second and third years of the six nursing majors. They were included in the study since they had completed several clinical placements and were in constant contact with the clinical teachers. First-year students, on the other hand, were not considered since they had not yet completed any clinical rotations at the time of the study.

The Knox and Mogan (1987) questionnaire on the effectiveness of clinical nursing instruction (NCTEI) was used to collect data ( J. Knox \& Mogan, 1985).

It is a 47 -item questionnaire on a 7 -point Likert scale. It consists of five dimensions characterizing clinical teaching, namely, clinical teaching ability, nursing competence, evaluation, interpersonal relationship, and personality.

Prior to their participation in the study, the participants were informed about the study's goal and the data collecting tool.

The questionnaire was administered online to all the participants because the study coincided with the lockdown period due to the Covid 19 outbreak, and the data were collected between the months of June and July 2020.

\subsection{Analyzing of Data}

The data collected from the NCTEI questionnaire were analyzed using SPSS software version 20. Descriptive statistics were performed (frequency, average, standard deviation) for the five dimensions of the questionnaire, as well as for the 47 constituent items. In addition, the non-parametric Mann Whitney test was used to investigate perceptual differences between the two groups of students.

\subsection{Ethical Considerations}

The present study received the ethical consent by the local ethics committee at ISPITS in Casablanca, Morocco. In addition, free and informed consent was obtained from all study participants. In addition, the anonymity and confidentiality of the data were respected.

\section{Results}

\subsection{Reliability of the measuring instrument}

Cronbach's Alpha coefficients attest to a very good reliability of the subscales of our measurement instrument. This latter ranges from 0.85 to 0.88 with $\alpha=0.95$ for the entire scale. We can therefore conclude that this is a consistent instrument in term of measurement. 


\section{Analysis of the Questionnaire}

\subsection{Participants' socio-demographic characteristics}

The socio-demographic data from 138 participants reveals a relatively youthful group of students aged 19 to 24 years old $(98.4 \%)$, with a majority of women (84.05 percent), of Moroccan nationality, who are majored in a variety of nursing options (Table 1 ).

Table 1: Socio-Demographic Characteristics of Participants

\begin{tabular}{|c|c|c|c|}
\hline \multirow{2}{*}{ No } & \multirow{2}{*}{ Demographic Characteristics } & \multicolumn{2}{|c|}{ Student (n/\%) } \\
\hline & & Total & $\%$ \\
\hline \multirow{3}{*}{1.} & Gender & & \\
\hline & Male & 22 & 15.94 \\
\hline & Female & 116 & 84.05 \\
\hline \multirow{3}{*}{2.} & Age & & \\
\hline & Under 19 years old & 02 & 1.6 \\
\hline & 19 and 24 years old & 136 & 98.4 \\
\hline \multirow{3}{*}{3.} & Nationality & & \\
\hline & Moroccan & 132 & 95.6 \\
\hline & Other & 6 & 4.3 \\
\hline \multirow{3}{*}{$4 \cdot$} & Year of study & & \\
\hline & 2nd year & 82 & 59.4 \\
\hline & 3rd year & 56 & 40.6 \\
\hline \multirow{7}{*}{5.} & Options of the nursing field & & \\
\hline & Polyvalent nurse & 62 & 44.9 \\
\hline & Nurse in anesthesia and intensive care & 11 & 8 \\
\hline & Emergency and Critical Care Nurse & 20 & 14.5 \\
\hline & Mental Health Nurse & 7 & 5.1 \\
\hline & Neonatal and Pediatric Nurse & 31 & 22.5 \\
\hline & Family and Community Health Nurse & 7 & 5.1 \\
\hline
\end{tabular}

\subsection{Students' perception of the dimensions of clinical teaching}

Concerning the dimension of teaching ability, students express a positive perception when it comes to interactivity and autonomy. Indeed, the highest-scoring items are related to these two aspects: answers carefully and precisely the questions raised by the students (4.99 \pm 1.84 ), encouraging active participation during discussions $(4.86 \pm 1.95)$, and promoting student's independence $(4.83 \pm 1.95)$ (Table 2).

Table 2: Students' Perception of the Dimensions of Clinical Teaching

\begin{tabular}{|c|c|c|c|}
\hline Item & Description & Average & Standard deviation \\
\hline 1. & Explains clearly & 4.57 & 1.88 \\
\hline 2. & Emphasizes what is important & 4.54 & 1.93 \\
\hline 3. & Stimulates students' interest in the subject & 4.42 & 1.87 \\
\hline 4. & Remains accessible to students & 4.53 & 1.86 \\
\hline 5. & Demonstrates clinical procedures and techniques & 4.75 & 1.87 \\
\hline 6. & Guides students toward developing clinical skills & 4.61 & 1.96 \\
\hline 7. & Provides specific practice opportunity & 4.33 & 1.99 \\
\hline 8. & Offers special help when difficulties arise & 4.38 & 1.98 \\
\hline 9. & Is well prepared for teaching & 4.64 & 1.86 \\
\hline 10. & Enjoys teaching & 4.61 & 2 \\
\hline
\end{tabular}




\begin{tabular}{|l|l|c|c|}
\hline Item & Description & Average & Standard deviation \\
\hline 11. & Encourages active participation during discussion. & 4.86 & 1.95 \\
\hline 12. & Gears instructions to students' level of readiness & 4.59 & 1.81 \\
\hline 13. & Quickly grasps what students are asking or telling & 4.49 & 1.81 \\
\hline 14. & Answers carefully and precisely to questions raised by students & 4.99 & 1.84 \\
\hline 15. & Questions students to elicit underlying reasoning & 4.75 & 1.78 \\
\hline 16. & Helps students organize their thoughts about patient problems & 4.52 & 1.93 \\
\hline 17. & promotes student independence & 4.83 & 1.95 \\
\hline
\end{tabular}

However, the aspects related to practice and assistance are the least scored; they offer specific help when difficulties arise (4.38 \pm 1.98$)$ and provide specific practice opportunities (4.33 \pm 1.99$)$.

For the dimension, "Nursing competence", students value the teacher when he or she assumes responsibility $(4.77 \pm 2.02)$, is conscious of his or her limitations $(4.72 \pm 2.02)$, and demonstrates sufficient nursing knowledge (4.70 \pm 1.86$)$ (Table 3 ).

Table 3: Students 'perception of the dimension of nursing competence in clinical teaching

\begin{tabular}{|l|l|l|l|}
\hline Item & Description & Average & Standard deviation \\
\hline $\mathbf{1 8 .}$ & Demonstrates clinical skills judgment & 4.12 & 1.82 \\
\hline $\mathbf{1 9 .}$ & Demonstrates communication skills & 4.39 & 1.74 \\
\hline $\mathbf{2 0 .}$ & Reveals broad reading in his/her area of interest & 4.41 & 1.80 \\
\hline $\mathbf{2 1 .}$ & Discusses current development in his/her field & 4.40 & 1.93 \\
\hline $\mathbf{2 2 .}$ & Directs students to useful literature in nursing & 4.62 & 1.96 \\
\hline $\mathbf{2 3 .}$ & Demonstrates a breadth of knowledge in nursing & 4.70 & 1.86 \\
\hline $\mathbf{2 4 .}$ & Recognizes own limitations & 4.72 & 2.02 \\
\hline $\mathbf{2 5 .}$ & Takes responsibility of own actions & 4.77 & 2.02 \\
\hline $\mathbf{2 6 .}$ & Is a good role model & 4.55 & 1.98 \\
\hline
\end{tabular}

Regarding the dimension of " Evaluation " in clinical teaching, students consider that the communication of expectations, frequent observation of their performance, and receiving constructive suggestions from their teachers are the most important $(4.42 \pm 2.02 ; 4.37 \pm 1.95 ; 4.30 \pm 1.80)$ (Table 4).

Table 4: Students' Perceptions of the Evaluation dimension in clinical teaching

\begin{tabular}{|l|l|c|c|}
\hline Item & Description & Average & $\begin{array}{c}\text { Standard } \\
\text { Deviation }\end{array}$ \\
\hline 27. & Makes specific suggestions for improvement & 4.30 & 1.80 \\
\hline $\mathbf{2 8 .}$ & Provides frequent feedback on students' performance & 4.22 & 1.75 \\
\hline 29. & Identifies students' strengths and limitations objectively & 4.27 & 1.91 \\
\hline 30. & Observes students' performance frequently & 4.37 & 1.95 \\
\hline 31. & Communicates expectations of students & 4.42 & 2.02 \\
\hline 32. & $\begin{array}{l}\text { Gives students positive reinforcement for good contributions, } \\
\text { observations, or performance. }\end{array}$ & 4.26 & 1.97 \\
\hline 33. & Corrects students' mistakes without belittling them & 4.21 & 2.10 \\
\hline 34. & Does not criticize students in front of others & 3.59 & 2.22 \\
\hline
\end{tabular}

Nevertheless, they were not satisfied with the criticism they received in front of others and the way their mistakes were corrected $(4.21 \pm 2.10 ; 3.59 \pm 2.22)$.

Concerning the dimension "interpersonal relationship", students credit more scores to the characteristics of respect, listening and showing interest from the teacher towards the student (4.62 $\pm 2.03 ; 4 \cdot 53 \pm 2.06 ; 4 \cdot 32 \pm 2.01$ ) (Table 5 ). 
Table 5: Students' perception of the interpersonal relationship in clinical teaching

\begin{tabular}{|l|l|c|c|}
\hline Item & Description & Average & $\begin{array}{c}\text { Standard } \\
\text { Deviation }\end{array}$ \\
\hline 35 & Provides support and encouragement to students & 4.28 & 2.06 \\
\hline 36 & Is approachable & 4.19 & 1.90 \\
\hline 37 & Encourages a climate of mutual respect & 4.62 & 2.03 \\
\hline $\mathbf{3 8}$ & listens attentively & 4.53 & 2.06 \\
\hline $\mathbf{3 9}$ & Shows personal interest in students & 4.32 & 2.01 \\
\hline $\mathbf{4 0}$ & Demonstrates empathy & 4.19 & 2 \\
\hline
\end{tabular}

The dimension "Personality" also elicits students' appreciation which is generally positive when the teacher expresses self-confidence and appears organized (4.83 $\pm 1.95 ; 4.77 \pm 1.99)$, However, the least scored aspect is related to openness and expression of judgment (4.09 \pm 1.97$)$ (Table 6).

Table 6: Students' perception of the personality dimension in clinical teaching

\begin{tabular}{|l|l|c|c|}
\hline Item & Description & Average & $\begin{array}{c}\text { Standard } \\
\text { Deviation }\end{array}$ \\
\hline 41. & Demonstrates enthusiasm & 4.12 & 1.90 \\
\hline $\mathbf{4 2 .}$ & Is a Dynamic and energetic person & 4.51 & 1.90 \\
\hline $\mathbf{4 3 .}$ & Self-confidence & 4.83 & 1.95 \\
\hline $\mathbf{4 4 .}$ & Is self-critical & 4.23 & 1.89 \\
\hline $\mathbf{4 5 .}$ & Is open-minded and non-judgmental & 4.09 & 1.97 \\
\hline $\mathbf{4 6 .}$ & Has a good sense of humor & 4.12 & 1.96 \\
\hline $\mathbf{4 7 .}$ & Appears organized & 4.77 & 1.99 \\
\hline
\end{tabular}

In terms of the overall evaluation to the clinical teaching, we found out that the students' teaching skills received the highest score $(4.61 \pm 1.62)$, followed by the aspects of nursing competence, personality, and interpersonal interaction.

Nevertheless, students assign the last place to the evaluation dimension $(4.20 \pm 1.76)$

\subsection{A comparison of students' perception to the dimensions of clinical teaching}

Analysis of the results shows differences in perceptions between the two groups of students for the five dimensions studied. Second year students give more importance to personality followed by interpersonal relationship and nursing competence and put evaluation last. Third year students on the other hand, favor nursing competence over interpersonal relationship, and evaluation, and put personality last (Table 7).

Table 7: A comparison of the dimensions of clinical teaching between the two groups of students

\begin{tabular}{|l|l|c|c|c|c|c|}
\hline \multicolumn{2}{|c|}{ Grade of study } & $\begin{array}{c}\text { Teaching } \\
\text { ability }\end{array}$ & $\begin{array}{c}\text { Nursing } \\
\text { competence }\end{array}$ & Evaluation & $\begin{array}{c}\text { Interpersonal } \\
\text { relationship }\end{array}$ & Personality \\
\hline \multirow{5}{*}{$\begin{array}{l}\text { Second } \\
\text { year } \\
\text { student }\end{array}$} & $\mathrm{N}$ & 82 & 82 & 82 & 82 & 82 \\
\cline { 2 - 7 } & Average & 4,49 & 4,41 & 4,13 & 4,30 & 4,43 \\
\cline { 2 - 7 } & DS & 1,70 & 1,72 & 1,83 & 1,83 & 367 \\
\cline { 2 - 7 } & $\begin{array}{l}\text { Average } \\
\text { rank }\end{array}$ & 368,47 & 362,00 & 338,75 & 353,33 & 70.26 \\
\cline { 2 - 7 } & $\begin{array}{l}\text { Sum of } \\
\text { ranks }\end{array}$ & 5514.00 & 66.98 & 67.96 & 68.24 & 5761.50 \\
\hline
\end{tabular}




\begin{tabular}{|l|l|c|c|c|c|c|}
\hline \multicolumn{2}{|c|}{ Grade of study } & $\begin{array}{c}\text { Teaching } \\
\text { ability }\end{array}$ & $\begin{array}{c}\text { Nursing } \\
\text { competence }\end{array}$ & Evaluation & $\begin{array}{c}\text { Interpersonal } \\
\text { relationship }\end{array}$ & Personality \\
\hline \multirow{4}{*}{$\begin{array}{l}\text { Third } \\
\text { year }\end{array}$} & $\mathrm{N}$ & 56 & 56 & 56 & 56 & 56 \\
\cline { 2 - 7 } Student & Average & 4,78 & 4,67 & 4,31 & 4,41 & 4,29 \\
\cline { 2 - 7 } & DS & 1,49 & 1,65 & 1,66 & 1,89 & 2,79 \\
\cline { 2 - 7 } & Sum & 267,47 & 261,67 & 241,50 & 247,50 & 240,71 \\
\cline { 2 - 7 } & Average & 72.80 & 73.20 & 71.75 & 71.35 & 68.38 \\
\cline { 2 - 7 } & $\begin{array}{l}\text { Sum of } \\
\text { ranks }\end{array}$ & 4077.00 & 4099.00 & 4018.00 & 3995.50 & 3829.50 \\
\hline \multicolumn{2}{|l|}{$\begin{array}{l}\text { Mann-Whitney U } \\
\text { significance }\end{array}$} & 2111.000 & 2089.000 & 2170.000 & 2192.500 & 2233.500 \\
\hline
\end{tabular}

Based on the statistical comparison of the differences between the two groups of students, the nonparametric Mann Whitney test for two independent samples was used instead of the Student's T-test. When the average rank of the five dimensions, namely teaching ability, nursing competence, evaluation, interpersonal relationship, and personality, is compared between the two groups, no statistically significant differences in students' perceptions of clinical teaching are found, with $\mathrm{p}$ greater than 0.05 for all dimensions.

\section{Discussion}

This study investigated the perception of students on the dimensions of clinical teaching in the nursing field at the Higher Institute of Nursing and Health Techniques in Casablanca. Its findings reveal disparities in how students rank the five dimensions of clinical instruction in terms of significance, as well as how they rate the many constituent items. However, the differences were not statistically significant.

For students, the most important dimension in clinical teaching was teaching skills $(4.61 \pm 1.62)$. This result is consistent with the results of Bifftu \& al. (2018) and Lovric \& al. (2017) who found that teaching ability is the most rated dimension among students (Bifftu et al., 2018; Lovrić et al., 2017). In the same vein, the study conducted by Knox and Mogan (1985) showed that this dimension is scored higher in second-year students compared to third-year students (J. E. Knox \& Mogan, 1985). Hababeh's (2020) findings, on the other hand, are paradoxical, since teaching ability is the lowestscored characteristic in students who have completed less than 12 months of clinical placement (Hababeh \& Lalithabai, 2020).

Furthermore, the ranking of other dimensions among students is as follows: nursing competence, personality, interpersonal relationship and lastly evaluation. As it is pointed out by Wang \& al. (2017), the five most scored items are related to the teacher's nursing competence (Wang et al., 2017). Also, Salizar \& al. (2016) insist on the influence of the teacher's nursing competence on the student's learning (Ludin \& Fathullah, 2016). Still, it remains the least important dimension in first year students according to the study of Lovric \& al. (2017) (Lovrić et al., 2017).

The findings also reveal variations in student perceptions of the five characteristics, with second-year students prioritizing personality over nursing competence, and third-year students placing nursing competence over personality. They both, however, place teaching abilities at the top of the list.

Answering students' questions thoroughly and accurately, being confident, promoting student independence, looking organized, and encouraging active involvement during discussion were the five most essential elements, listed by the students. Indeed, practical knowledge is constructed through social dialogue between students, clinical nurses and nursing faculty (Lillekroken, 2019). Students have opportunities to ask questions in order to get new knowledge and advance their level of learning, while teachers can offer responses at the same moment, ensuring by this way continuous 
feedback (Havery, 2019; Lillekroken, 2019).

However, the five least important items are ; being open-minded and non-judgmental, having a good sense of humor and demonstrating enthusiasm, having clinical and judgmental skills, and not criticizing students in front of others. In reality, numerous research show that the dimensions of personality and evaluation are of greater interest to students; still personality is ranked higher than evaluation among students (Soriano \& Aquino, 2017). These two dimensions received the same third ranking and score among students (Gangadharan et al., 2016). However, students ranked evaluation higher than personality, particularly the significance of obtaining feedback (Bifftu et al., 2018). With student placing the highest score for evaluation and the lowest score for personality (J. E. Knox \& Mogan, 1985), these two dimensions characterize the best clinical teaching according to students (Nehring, 1990a). It is evident then that they are at the top of the dimensions list for all students, except those who have completed less than a year of clinical placement (Hababeh \& Lalithabai, 2020).

This significant interest in personality arises from the need to have a clinical teacher who frequently shows a smile and excitement and encourages students to acquire these caring and humanistic traits with patients. He is someone who defends them in the clinical setting during challenging circumstances, intending to socialize them with the nursing profession (Parsh, 2009). Moreover, the supervision of students in the clinical setting is based on the feedback given to the student right after the patient's care. This helps the student to improve his or her learning experience and provides further opportunities for authentic learning (Havery, 2019; Scott \& Elliott, 2019; Takashima et al., 2019). Furthermore, students want clear, personalized feedback to discover their strengths and shortcomings and to fix their mistakes within the context of a respectful and trustworthy relationship with the teacher (Chan et al., 2017).

Thus, the dimension of evaluation is not equally significant in the both groups because secondyear students rank it last. Nonetheless, learning situations, supervision, and assessment contribute strongly to students' authentic learning in the clinical setting (Takashima et al., 2019). In contrast, third-year students give importance to assessment and put personality last. This difference in the ranking of the evaluation dimension compared to other studies can be attributed , on the one hand, to the variations in the country's socioeconomic status, personal character, and environment especially with technological advances (Fraser et al., 2010; Rademakers et al., 2011). On the other hand, it can be attributed to a shift in traditional teaching methods through integrated teaching, problem-based learning, and a greater emphasis on performance assessment techniques such as objective structured clinical examinations, the use of standardized patients, logbooks, portfolio assessment, and selfassessment, putting students at the center of attention (Harden \& Crosby, 200o).

Statistical comparison of the differences between the two groups of students, using the nonparametric Mann Whitney test for the two independent samples, showed that the differences in students' perception on the dimensions of clinical teaching were not statistically significant with $\mathrm{p}$ greater than 0.05 for all dimensions. However, most studies that have investigated differences in the perception of the dimensions of quality clinical teaching in nursing education, have compared students' perception with those of teachers and tutors. (Bifftu et al.,2018; Gangadharan et al., 2016; Hababeh \& Lalithabai, 2020; J. E. Knox \& Mogan, 1985; Lovrić et al., 2017; Nehring, 199ob; Soriano \& Aquino, 2017). These differences are broadly related to the five dimensions of clinical teaching effectiveness; teaching ability, nursing competence, evaluation, interpersonal relationship and personality.

Nonetheless, Knox and Mogan (1985) identified major differences in students' perceptions of clinical teaching characteristics at all four levels of study (J. E. Knox \& Mogan, 1985). Lovric \& al. (2017) also demonstrate differences in students' perceptions of the three levels (Lovrić et al., 2017). Similarly, Hababeh (2020) found out that most students, except for those who have completed between 7 and 12 months of internship, perceive only three dimensions: teaching skill, nursing competence, and interpersonal interaction with a p value less than 0.05 (Hababeh \& Lalithabai, 2020). From the reasons mentioned above, it is of great necessity to study the perceptions of clinical teachers and tutors on clinical teaching and compare them with those of their students to highlight 
differences and commonalities. Likewise, it is equal importance to investigate the various factors behind these differences in perception.

\section{Conclusion}

Student evaluation of teaching is a process of gathering information from students about the teaching or the learning process they have experienced in one or more courses. It is a form of evaluation that has been developed to improve teaching operation from a formative evaluation perspective. Moreover, the objective of this study was to explore and compare students' perceptions of their clinical teaching experience. The comparison of students' perceptions showed differences but were not statistically significant. For nursing students, while teaching ability ranked first followed by nursing competence, personality, and interpersonal relationship, the evaluation dimension was ranked last.

This study has given us an insight into the characteristics of clinical teaching from a student perspective. However, more research that involves clinical teachers and tutors is required to investigate the differences between the three groups. Furthermore, the causes behind these differences must be investigated in order to provide a more comprehensive and fuller picture to the issue.

\section{References}

Annan, S. L., Tratnack, S., Rubenstein, C., Metzler-Sawin, E., \& Hulton, L. (2013). An Integrative Review of Student Evaluations of Teaching: Implications for Evaluation of Nursing Faculty. Journal of Professional Nursing, 29(5), e10-e24. https://doi.org/10.1016/j.profnurs.2013.06.004

Bifftu, B. B., Dachew, B. A., Tiruneh, B. T., Ashenafie, T. D., Tegegne, E. T., \& Worku, W. Z. (2018). Effective Clinical Teaching Behaviors Views of Nursing Students and Nurse Educators at University of Gondar, Northwest Ethiopia: Cross-Sectional Institution Based Study. Journal of Caring Sciences, 7(3), 119-123. https://doi.org/10.15171/jcs.2018.019

Boyd, P., \& Lawley, L. (2009). Becoming a lecturer in nurse education: The work-place learning of clinical experts as newcomers. Learning in Health and Social Care, 8(4), 292-300. https://doi.org/10.1111/j.14736861.2009.00214.x

Brown, J., Stevens, J., \& Kermode, S. (2012). Supporting student nurse professionalisation: The role of the clinical teacher. Nurse Education Today, 32(5), 606-610. https://doi.org/10.1016/j.nedt.2011.08.007

Bush, M. A., Rushton, S., Conklin, J. L., \& Oermann, M. H. (2018). Considerations for Developing a Student Evaluation of Teaching Form. Teaching and Learning in Nursing, 13(2), 125-128. https://doi.org/10.1016/j.teln.2017.10.002

Castro-Yuste, C., García-Cabanillas, M. J., Rodríguez-Cornejo, M. J., Carnicer-Fuentes, C., Paloma-Castro, O., \& Moreno-Corral, L. J. (2018). A Student Assessment Tool for Standardized Patient Simulations (SAT-SPS): Psychometric analysis. Nurse Education Today, 64, 79-84. https://doi.org/10.1016/j.nedt.2018.02.005

Chan, Z. C., Tong, C. W., \& Henderson, S. (2017). Power dynamics in the student-teacher relationship in clinical settings. Nurse Education Today, 49, 174-179. https://doi.org/10.1016/j.nedt.2016.11.026

Cho, J. I., Hamash, K., Otani, K., Reimer, N., \& Deng, Y. (2018). Influential Factors of Student Evaluations of Teaching in a Nursing Program. Teaching and Learning in Nursing, 13(2), 86-94. https://doi.org/10.1016/j.teln.2018.01.002

Cho, J.-I., Otani, K., \& Kim, B. J. (2014). Differences in Student Evaluations of Limited-Term Lecturers and FullTime Faculty. Journal on Excellence in College Teaching, 25(2), 5-24.

Creative Commons Legal Code. (n.d.). University of British Columbia Library. Retrieved October 25, 2021, from https://creativecommons.org/licenses/by-nc-sa/3.o/legalcode

Creative Commons-Attribution-NonCommercial-ShareAlike 3.o Unported-CC BY-NC-SA 3.o. (n.d.). University of British Columbia Library. Retrieved October 25, 2021, from https://creativecommons.org/licenses/by-nc$\mathrm{sa} / 3.0 /$

Edberg, A.-K., \& Lilja Andersson, P. (2015). The shift from a medical to a nursing orientation: A comparison of Swedish nursing students' expectations when entering the nursing degree programme in 2003 and 2013. Nurse Education Today, 35(9), e78-e83. https://doi.org/10.1016/j.nedt.2015.06.015

Elcigil, A., \& Sari, H. Y. (2008). Students' Opinions About and Expectations of Effective Nursing Clinical Mentors. Journal of Nursing Education, 47(3), 118-123. https://doi.org/10.3928/01484834-20080301-07 
Fraile, R., \& Bosch-Morell, F. (2015). Considering teaching history and calculating confidence intervals in student evaluations of teaching quality: An approach based on Bayesian inference. Higher Education, 70(1), 55-72. https://doi.org/10.1007/s10734-014-9823-0

Fraser, B. J., Aldridge, J. M., \& Soerjaningsih, W. (2010). Instructor-Student Interpersonal Interaction and Student Outcomes at the University Level in Indonesia !2009-08-15 !2009-01-08 !2010-03-09 ! The Open Education Journal, 3(1), 21-33. https://doi.org/10.2174/1874920801003010021

Gangadharan, P., AlWahed, M. A. A., \& Assiri, M. M. A. (2016). Effectiveness of clinical teacher behaviors as perceived by nursing students, graduates and faculty of king khalid university, college of applied medical science, mohail, kingdom of saudi arabia. International Journal of Current Advanced Research, 5(3), 651-656.

Hababeh, M. O., \& Lalithabai, D. S. (2020). Nurse trainees' perception of effective clinical instructor characteristics. International Journal of Nursing Sciences, 7(3), 285-290. https://doi.org/10.1016/j.ijnss.2020.06.006

Hallin, K. (2014). Nursing students at a university-A study about learning style preferences. Nurse Education Today, 34(12), 1443-1449. https://doi.org/10.1016/j.nedt.2014.04.001

Harden, R. M., \& Crosby, J. (2000). AMEE Guide No 20: The good teacher is more than a lecturer-The twelve roles of the teacher. $22(20), 14$.

Havery, C. (2019). The effects of clinical facilitators' pedagogic practices on learning opportunities for students who speak English as an additional language: An ethnographic study. Nurse Education Today, 74, 1-6. https://doi.org/10.1016/j.nedt.2018.12.004

Hsu, L.-L. (2014). Clinical teaching competence inventory for nursing preceptors: Instrument development and testing. 46(2), 214-224.

Kamonratananun, N., Sujiva, S., \& Tangdhanakanond, K. (2016). Development of an Evaluation Capacity-Building Program for Nurse Teachers in Students' Practicum. Procedia - Social and Behavioral Sciences, 217, $344-353$. https://doi.org/10.1016/j.sbspro.2016.02.100

Knox, J. E., \& Mogan, J. (1985). Important clinical teacher behaviours as perceived by university nursing faculty, students and graduates. Journal of Advanced Nursing, 10(1), 25-30. https://doi.org/10.1111/j.13652648.1985.tboo488.x

Knox, J., \& Mogan, J. (1985). Nursing Clinical Teacher Effectiveness Inventory [Text]. The University of British Columbia. https://open.library.ubc.ca/collections/52383/items/1.0084583

Lee, W.-S. (Christina), Cholowski, K., \& Williams, A. K. (2002). Nursing students' and clinical educators' perceptions of characteristics of effective clinical educators in an Australian university school of nursing. Journal of Advanced Nursing, 39(5), 412-420. https://doi.org/10.1046/j.1365-2648.2002.02306.x

Lillekroken, D. (2019). Nursing students' perceptions towards being taught the fundamentals of care by clinical nurses within a simulated learning environment: A qualitative study. Nurse Education in Practice, 36, 76-81. https://doi.org/10.1016/j.nepr.2019.03.010

Lovrić, R., Prlić, N., Barać, I., Plužarić, J., Pušeljić, S., Berecki, I., \& Radić, R. (2014). Specificities and Differences in Nursing Students' Perceptions of Nursing Clinical Faculties' Competences. Journal of Professional Nursing, 30(5), 406-417. https://doi.org/10.1016/j.profnurs.2014.03.005

Lovrić, R., Prlić, N., Milutinović, D., Marjanac, I., \& Žvanut, B. (2017). Changes in nursing students' expectations of nursing clinical faculties' competences: A longitudinal, mixed methods study. Nurse Education Today, 59, 38-44. https://doi.org/10.1016/j.nedt.2017.08.013

Ludin, S. M., \& Fathullah, N. M. N. (2016). Undergraduate nursing students' perceptions of the effectiveness of clinical teaching behaviours in Malaysia: A cross-sectional, correlational survey. Nurse Education Today, 44, 79-85. https://doi.org/10.1016/j.nedt.2016.05.007

Nahas, V. L., Nour, V., \& Al-Nobani, M. (1999). Jordanian undergraduate nursing students' perceptions of effective clinical teachers. Nurse Education Today, 19(8), 639-648. https://doi.org/10.1054/nedt.1999.0376

Navabi, N., Ghaffari, F., Shamsalinia, A., \& Faghani, S. (2016). Development and validation of evaluation tools of nursing students\&rsquo; clinical pharmacology unit. Drug, Healthcare and Patient Safety, Volume 8, $101-109$. https://doi.org/10.2147/DHPS.S110774

Nehring, V. (1990a). Nursing Clinical Teacher Effectiveness Inventory: A replication study of the characteristics of "best" and "worst" clinical teachers as perceived by nursing faculty and students. Journal of Advanced Nursing, 15(8), 934-940. https://doi.org/10.1111/j.1365-2648.1990.tbo1949.X

Nehring, V. (1990b). Nursing Clinical Teacher Effectiveness Inventory: A replication study of the characteristics of "best" and "worst" clinical teachers as perceived by nursing faculty and students. Journal of Advanced Nursing, 15(8), 934-940. https://doi.org/10.1111/j.1365-2648.1990.tbo1949.x 
O’Mara, L., McDonald, J., Gillespie, M., Brown, H., \& Miles, L. (2014). Challenging clinical learning environments: Experiences of undergraduate nursing students. Nurse Education in Practice, 14(2), $208-213$. https://doi.org/10.1016/j.nepr.2013.08.012

Otani, K., Kim, B. J., \& Cho, J.-I. (2012). Student Evaluation of Teaching (SET) in Higher Education: How to Use SET More Effectively and Efficiently in Public Affairs Education. Journal of Public Affairs Education, 18(3), 531-544. https://doi.org/10.108o/15236803.2012.12001698

Otti, A., Pirson, M., \& Piette, D. (2015). Perception des encadrants de stage du processus de gestion et de la qualité de l'encadrement pédagogique clinique en sciences infirmières et obstétricales au Bénin.[Internship supervisors' perception of the management process and the quality of clinical teaching supervision in nursing and obstetrics in Benin]. Nursing research/Recherche en soins infirmiers, $123(4), 77$. https://doi.org/10.3917/rsi.123.0077

Papathanasiou, I. V., Tsaras, K., \& Sarafis, P. (2014). Views and perceptions of nursing students on their clinical learning environment: Teaching and learning. Nurse Education Today, 34(1), 57-6o. https://doi.org/10.1016/j.nedt.2013.02.007

Parsh, B. (2009). Nursing student and faculty perceptions of the characteristics of effective instructors in the simulated clinical experience [Doctoral Dissertations]. The University of San Francisco.

Rademakers, J., Delnoij, D., \& de Boer, D. (2011). Structure, process or outcome: Which contributes most to patients' overall assessment of healthcare quality? BMJ Quality $\mathcal{E}$ Safety, 20(4), 326-331. https://doi.org/10.1136/bmjqs.2010.042358

Rodger, K. (2019). Learning to Think Like a Clinical Teacher. Teaching and Learning in Nursing, 14(1), 1-6. https://doi.org/10.1016/j.teln.2018.08.001

Salamonson, Y., Everett, B., Halcomb, E., Hutchinson, M., Jackson, D., Mannix, J., Peters, K., \& Weaver, R. (2015a). Unravelling the complexities of nursing students' feedback on the clinical learning environment: A mixed methods approach. Nurse Education Today, 35(1), 206-211. https://doi.org/10.1016/j.nedt.2014.08.005

Salamonson, Y., Everett, B., Halcomb, E., Hutchinson, M., Jackson, D., Mannix, J., Peters, K., \& Weaver, R. (2015b). Unravelling the complexities of nursing students' feedback on the clinical learning environment: A mixed methods approach. Nurse Education Today, 35(1), 206-211. https://doi.org/10.1016/j.nedt.2014.08.005

Scott, C., \& Elliott, M. (2019). Flipped Clinical Preceptorship: An Alternate Model of Nursing Student Supervision. Teaching and Learning in Nursing, 14(1), 43-46. https://doi.org/10.1016/j.teln.2018.09.005

Selim, A. A., Ramadan, F. H., El-Gueneidy, M. M., \& Gaafer, M. M. (2012). Using Objective Structured Clinical Examination (OSCE) in undergraduate psychiatric nursing education: Is it reliable and valid? Nurse Education Today, 32(3), 283-288. https://doi.org/10.1016/j.nedt.2011.04.006

Setari, A. P., Lee, J., \& Bradley, K. D. (2016). A psychometric approach to the validation of a student evaluation of teaching instrument. Studies in Educational Evaluation, 51, 77-87. https://doi.org/10.1016/j.stueduc.2016.09.006

Shahsavari, H., Yekta, Z. P., Zare, Z., \& Sigaroodi, A. E. (2014). Iranian Effective Clinical Nurse Instructor evaluation tool: Development and psychometric testing. Iranian Journal of Nursing and Midwifery Research, $19(2), 8$.

Soriano, G. P., \& Aquino, Ma. G. B. (2017). Characteristics, Clinical Teacher, Nursing Students, Faculty Members. International Journal of Nursing Science, 7(4), 96-101. https://doi.org/10.5923/j.nursing.20170704.04

Takashima, M., Burmeister, E., Ossenberg, C., \& Henderson, A. (2019). Assessment of the clinical performance of nursing students in the workplace: Exploring the role of benchmarking using the Australian Nursing Standards Assessment Tool (ANSAT). Collegian, 26(4), 502-506. https://doi.org/10.1016/j.colegn.2019.01.005

Uttl, B., White, C. A., \& Gonzalez, D. W. (2017). Meta-analysis of faculty's teaching effectiveness: Student evaluation of teaching ratings and student learning are not related. Studies in Educational Evaluation, 54, 22-42. https://doi.org/10.1016/j.stueduc.2016.08.007

Wang, X., Zhao, L., Hu, H., Ou, G., \& Liao, L. (2017). Competence of clinical teachers: A survey on perception of masters of nursing specialist postgraduates, their clinical teachers, and head nurses. International Journal of Nursing Sciences, 4(2), 158-163. https://doi.org/10.1016/j.ijnss.2017.03.005

Zabaleta, F. (2007). The use and misuse of student evaluations of teaching. Teaching in Higher Education, 12(1), 5576. https://doi.org/10.108o/13562510601102131

Zakari, N. M. A., Hamadi, H. Y., \& Salem, O. (2014). Developing an understanding of research-based nursing pedagogy among clinical instructors: A qualitative study. Nurse Education Today, 34(11), $1352-1356$. https://doi.org/10.1016/j.nedt.2014.03.011 